\title{
Ethylene Yield from Pyrolysis Cracking in Olefin Plant Utilizing Regression Analysis
}

\author{
Mohamad Hafizi Zakria, ${ }^{1,2}$, Mohd Ghazali Mohd Nawawi ${ }^{1}$, and Mohd Rizal Abdul Rahman ${ }^{2,3}$ \\ ${ }^{1}$ School of Chemical and Energy Engineering, Faculty of Engineering, Universiti Teknologi Malaysia, 81310, Johor, Malaysia \\ ${ }^{2}$ Steam Cracker Complex, Pengerang Refining Company Sdn Bhd, PICMO B2, Pengerang Integrated Complex, 81600, Johor, Malaysia \\ ${ }^{3}$ PETRONAS Refinery and Petrochemicals Corporation Sdn Bhd, The Intermark Tower, 55000 Kuala Lumpur, Malaysia
}

\begin{abstract}
Ethylene yield is significant in showing the performance of the steam cracker furnace in the olefin plant. This study was conducted in the actual large-scale olefin plant to see the impact of various variables towards the ethylene yield. The analysis was conducted utilizing Regression Analysis in Minitab Software Version 18 to develop a reliable ethylene yield model. The model concluded that ethylene yield in the studied plant was contributed by the factor of $-0.000901,0.02649,-0.282,0.16,-0.0834,0.1268$, and 0.0057 of Hearth Burner Flow, Integral Burner Flow, Steam Drum Pressure, Super High-Pressure Steam (SHP) Boiler Feed Water Flow, SHP Flow, Naphtha Feed Flow, and Stack NOx Emission respectively. The Response Optimizer tool also showed that the ethylene yield from naphtha liquid feed utilizing pyrolysis cracking can be maximized at $32.55 \%$ with control setting at 9,476.41 kg/hr of Hearth Burner Flow, 608.56 $\mathrm{kg} / \mathrm{hr}$ of Integral Burner Flow, 112.93 Barg of Steam Drum Pressure, $109.11 \mathrm{t} / \mathrm{hr}$ of SHP Boiler Feed Water Flow, $86.42 \mathrm{t} / \mathrm{hr}$ of SHP Flow, $63.49 \mathrm{t} / \mathrm{hr}$ of Naphtha Feed Flow and $126.23 \mathrm{mg} / \mathrm{m}^{3}$ of Stack NOx Emission.
\end{abstract}

\section{Introduction}

The study was conducted in a newly commissioned olefin plant with naphtha liquid as a feedstock to the steam cracker furnace. The plant was designed to produce 1,100 KTA capacity of polymer grade ethylene product via pyrolysis cracking in the large-scale steam cracker furnace. Conducting the study in actual plant conditions is challenging as it is often affected by process fluctuation $[1,2]$ due to frequent variation in the upstream process, downstream readiness, utility availability, and feedstock composition.

Pyrolysis cracking causes hydrocarbon bonds to break resulted from a high-temperature cracking reaction $[3,4]$ and form the smaller and unsaturated molecule $[5$, 6] of olefin products such as ethylene and propylene. Ethylene plant utilizing pyrolysis cracking is special and usually defined as a core of the petrochemical industry $[7,8]$ as its performance may define the advancement of the petrochemical industry in the country [9].

There are various technologies provided by Olefin Plant Licensors worldwide which are Lummus, Linde, KBR, and Technip. Ethylene production from thermal cracking in the Short Residence Time (SRT) VII furnace is among the most promising technology available in the market $[10,11]$ due to its promising olefin yields and sustainable technology.
The feed specification during the study is shown in Table 1 while Fig. 1 shows the configuration of the steam cracker furnace with its auxiliaries in the studied plant.

Table 1. Naphtha feed condition at the studied plant

\begin{tabular}{|c|c|c|}
\hline \multirow{2}{*}{ Parameter } & \multicolumn{2}{|c|}{ Specification } \\
\cline { 2 - 3 } & Unit & Value \\
\hline Paraffins - (P) & $\%$ vol & 60.92 \\
\hline Olefins - (O) & $\%$ vol & 1.02 \\
\hline Naphthenes - (N) & $\%$ vol & 25.97 \\
\hline Aromatics - (A) & $\%$ vol & 12.09 \\
\hline Reid Vapour Pressure & $\mathrm{kPa}$ & 44.5 \\
\hline Density & $\mathrm{kg} / \mathrm{L}$ & 0.7248 \\
\hline TBP Distillation Curve & & \\
\hline Final Boiling Point & ${ }^{\circ} \mathrm{C}$ & 166.1 \\
\hline 70 vol - \% & ${ }^{\circ} \mathrm{C}$ & 125.8 \\
\hline 50 vol - \% & ${ }^{\circ} \mathrm{C}$ & 105.1 \\
\hline 30 vol - \% & ${ }^{\circ} \mathrm{C}$ & 84.4 \\
\hline Initial Boiling Point & ${ }^{\circ} \mathrm{C}$ & 34.1 \\
\hline Sulfur & $\mathrm{ppm} \mathrm{wt}$ & 298.5 \\
\hline
\end{tabular}

\footnotetext{
* Corresponding author: mohamadhafizi.zakri@prefchem.com;
} 


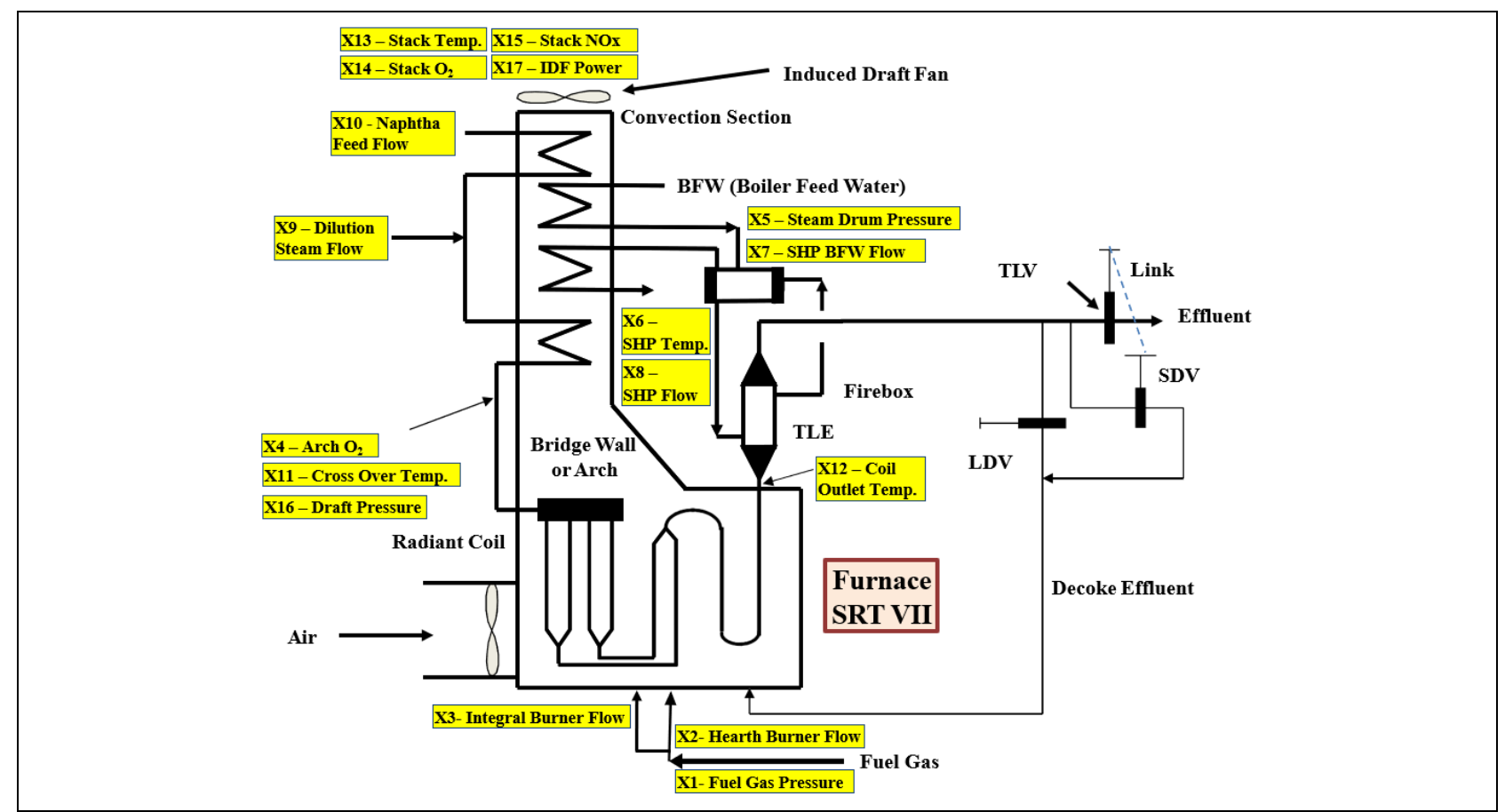

Fig. 1. General arrangement for SRT VII Furnace in the studied plant with tags and description of the chosen variables for the study

The naphtha feed starts entering the furnace from the first bank in the convection section and will mix with Dilution Steam (DS) at the middle bank. This mixing was designed to improve olefin selectivity mainly by reducing the partial pressure of naphtha feed $[12,13]$ and therefore will favor the ethylene yield from the reversible reaction following Le' Chatelier's Principles.

This naphtha and DS mixture is also known as the mixed feed. It will further flow into the radiation section that is having the operating Tube Metal Temperature (TMT) of the furnace coils at $1,050{ }^{\circ} \mathrm{C}-1,180{ }^{\circ} \mathrm{C}$. The cracked gas then will enter the Transfer Line Exchanger (TLE) for rapid cooling of effluent and Super High Pressure (SHP) Steam generation before sending the cracked gas to the downstream equipment for further process.

The furnace is the key in the ethylene production industry [14] where its performance will determine the yield and quality of ethylene [15] produced. Coke will be formed over time in the furnace coil resulted from the rapid cracking of naphtha feed in the furnace coil. The Decoke cycle is crucial in the olefin process to remove the hard coke from the furnace's coil. Transfer Line Valve (TLV) and Decoke Valve (DV) are connected via a mechanical link (shown by the blue dotted line). They will be used during the decoke cycle to route air and steam to the furnace coil to burn away the coke from the furnace's coil.

The mixture of air and steam is utilized to perform decoke activity according to the scheduled cycle to ensure continuous ethylene production [16] and sustainable normal cracking conditions [17] for the furnaces. Obtaining safe and stable operation including during the decoke cycle is one of the keys to ensure an excellent generation of ethylene yield in the steam cracker furnace $[18,19]$.

\section{Methods and Equipment}

\subsection{Equipment/Tools}

SRT VII furnace and its auxiliaries in the studied plant including Burners, Steam Drum, Induced Draft Fan (IDF), and TLEs were utilized for the study. This studied SRT VII furnace was designed by Lummus Technology Heat Transfer (LTHT), United States with $93 \mathrm{t} / \mathrm{hr}$ of processing capacity for the naphtha liquid. The furnace construction was completed by Toyo Engineering, Japan.

The process data for the required operating parameters were collected from Process Information Management System (PIMS) Software, PI Process Book Version 2015 while the analysis was conducted using Minitab Software Version 18.

\subsection{Methodology}

17 variables associated with the steam cracker furnace were identified to be included in the analysis. Each variable was given an individual tag namely $\mathrm{X} 1-\mathrm{X} 17$ as shown in Table 2. The location of each tag for the studied furnace was also shown in Fig. 1.

The tags are chosen without separation of "controlled" and "output" variables to see the relationship of all variables towards Ethylene Yield represented by $\mathrm{Y} 1$ as a whole. The analysis was conducted on $24^{\text {th }}$ Jan $2020,5.00$ pm until $2^{\text {nd }} F e b 2020$, $12.00 \mathrm{pm}$ (Malaysia Time, $211 \mathrm{hrs}$ total). The data was extracted from the PI Process Book on an hourly basis (average, time-weighted) with a total of 3,798 data (represented by 1 output and 17 input variables).

The data stability verification was first conducted utilizing three tools namely Box Plot, Run Chart, and Individual-Moving Range (I-MR) Chart. The step 
continued with data normality verification utilizing the Normality Test and Graphical Summary. All 3,798 data were analyzed using these 5 tools in Minitab Software Version 18 to identify normality and stability of data before the decision in conducting Regression analysis using normal and/or transformed data methodology.

The P-Value in both stability and normality check should be above 0.05 to proceed with Regression analysis as the normal data. The analysis will follow Box-Cox Transformation if the P-Value generated from these tools was lower than 0.05 .

The Regression was conducted a few times via one by one variable elimination in each Regression until all variables achieve VIF $<10$ and $\mathrm{P}$-Value $<0.05$. VIF is important in showing the multicollinearity relation in ordinary least squares for the Regression analysis. Value $>10$ is not recommended [20] as it could affect P-value significantly and contributed to the unreliable model.

The sequence of variable elimination started from the highest VIF value until all variables achieved VIF $<10$. Once achieved, the elimination continued with the highest P-Value until all variables recorded P-Value $<0.05$. After both VIF and P-Value requirements were met, Residual removal was conducted to the latest Regression model utilizing the Normality Plot and I-MR chart. The final Regression was conducted after clearance of these residuals and the model generated was taken as final.

Response Optimizer tool was also applied to the final model to predict the maximum value of ethylene yield with the significant process settings that can be obtained in the studied plant utilizing actual data and the final Regression model developed.

\section{Results and Discussion}

The Regression analysis utilizing Minitab Software was conducted a few times until all VIFs and P-Values reading were meeting requirements set in Section 2. These repetitive steps were conducted to ensure a reliable mathematical model being developed for Ethylene Yield represented by Y1. Table 2 shows the initial $\left(1^{\text {st }}\right)$ and final $\left(12^{\text {th }}\right)$ Regression analysis results conducted during the study. The final model developed after the $12^{\text {th }}$ Regression is shown in Eq. 1 .

$$
\begin{gathered}
Y 1=39.8-0.000901(X 2)+0.02649(X 3)- \\
0.282(X 5)+0.1600(X 7)-0.0834(X 8) \\
+0.1268(X 10)-0.00957(X 15)
\end{gathered}
$$

$1^{\text {st }}$ and $2^{\text {nd }}$ Regressions were conducted with the removal of variables with VIF $>10$, one by one. The VIF for all variables successfully reduced to $<10$ in the $3^{\text {rd }}$ Regression. Besides, some variables with VIF $>10$ in $1^{\text {st }}$ Regression such as X2 and X10 reduced to 9.4 and 9.75 respectively in the $3^{\text {rd }}$ Regression, and therefore these variables remained in the next Regression.

$3^{\text {rd }}-10^{\text {th }}$ Regressions were conducted with the removal of variables with P-Value $>0.05$. The sequence of elimination for $1^{\text {st }}-10^{\text {th }}$ Regression conducted were X13 (VIF: 19.16), X14 (VIF: 16.63), X1 (P-Value: 0.793), X9 (P-Value: 0.685), X11 (P-Value: 0.684), X4 (P-Value: 0.488), X16 (P-Value: 0.468), X17 (P-Value:

\begin{tabular}{|c|c|c|c|c|c|c|c|}
\hline \multirow{2}{*}{\multicolumn{2}{|c|}{ Tag and Description }} & \multicolumn{3}{|c|}{ Initial Regression $\left(1^{\text {st }}\right)$} & \multicolumn{3}{|c|}{ Final Regression $\left(12^{\text {th }}\right)$} \\
\hline & & Coefficient & P-Value & VIF & Coefficient & P-Value & VIF \\
\hline \multicolumn{2}{|c|}{ Constant } & 68.5 & 0.138 & & 39.8 & 0.017 & \\
\hline $\mathrm{X} 1$ & Fuel Gas Pressure & 0.221 & 0.389 & 3.14 & & & \\
\hline $\mathrm{X} 2$ & Hearth Burner Flow & -0.000553 & 0.002 & 10.76 & -0.000901 & 0.000 & 4.33 \\
\hline $\mathrm{X} 3$ & Integral Burner Flow & 0.02548 & 0.000 & 2.79 & 0.02649 & 0.000 & 2.58 \\
\hline $\mathrm{X} 4$ & $\mathrm{Arch} \mathrm{O}_{2}$ & 0.145 & 0.463 & 5.60 & & & \\
\hline $\mathrm{X} 5$ & Steam Drum Pressure & -0.363 & 0.014 & 4.92 & -0.282 & 0.038 & 3.99 \\
\hline X6 & SHP Temperature & -0.0409 & 0.053 & 3.62 & & & \\
\hline $\mathrm{X} 7$ & SHP BFW Flow & 0.0633 & 0.145 & 7.21 & 0.1600 & 0.000 & 3.89 \\
\hline $\mathrm{X} 8$ & SHP Flow & -0.0444 & 0.109 & 3.22 & -0.0834 & 0.001 & 2.52 \\
\hline X9 & Dilution Steam Flow & -0.000052 & 0.660 & 1.10 & & & \\
\hline $\mathrm{X} 10$ & Naphtha Feed Flow & 0.0837 & 0.035 & 12.62 & 0.1268 & 0.000 & 3.96 \\
\hline $\mathrm{X} 11$ & Crossover Temperature & 0.0157 & 0.799 & 10.05 & & & \\
\hline $\mathrm{X} 12$ & Coil Outlet Temp. & -0.0070 & 0.901 & 3.75 & & & \\
\hline $\mathrm{X} 13$ & Stack Temperature & 0.1554 & 0.114 & 19.16 & & & \\
\hline $\mathrm{X} 14$ & Stack $\mathrm{O}_{2}$ & -1.451 & 0.000 & 17.73 & & & \\
\hline $\mathrm{X} 15$ & Stack $\mathrm{NO}_{\mathrm{x}}$ & 0.00563 & 0.334 & 9.21 & -0.00957 & 0.014 & 3.87 \\
\hline $\mathrm{X} 16$ & Draft Pressure & 0.226 & 0.075 & 1.61 & & & \\
\hline $\mathrm{X} 17$ & Induced Fan Power & -0.0413 & 0.361 & 2.15 & & & \\
\hline
\end{tabular}
0.402), X6 (P-Value: 0.143) and X12 (P-Value: 0.349).

Table 2. Regression Analysis Result 
The final Regression model in Table 2 also showed that all significant variables successfully achieve a VIF of $<5$ in the model. The VIF of $<5$ is recommended [21] and better as it further reduced multicollinearity in the final model compared to VIF $<10$ obtained during $3^{\text {rd }}$ Regression.

Table 3 summarizes the final model developed from the analysis. The R-Square value of $76.85 \%$ is good considering the study was conducted in the actual largescale plant where process variation often occurred. It was also indicated that $76.85 \%$ of the variability in data was accounted for in the model. This value was adequate to explain the data variability which advised at more than $75 \%[22,23]$.

Table 3. Model summary

\begin{tabular}{|c|c|c|c|}
\hline S & R-sq & R-sq(adj) & R-sq(pred) \\
\hline 0.232533 & $76.85 \%$ & $75.95 \%$ & $74.22 \%$ \\
\hline
\end{tabular}

Fig. 2 shows the Contour Plot for the variables with the lowest P-Value in the final regression model. The Y1 which represented the Ethylene Yield was mapped with a prediction value of $<28.5->31.5$. This can be seen from the contour colors in the Contour Plot.

The variable of (X3 - Integral Burner Flow) vs (X2 Hearth Burner Flow) and (X7 - SHP BFW Flow) vs (X2 - Hearth Burner Flow) showed a most significant impact in realizing the highest (Y1 - Ethylene Yield). The higher reading of $\mathrm{X} 3$ and $\mathrm{X} 7$ combined with the lower reading of $\mathrm{X} 2$ in the studied plant may contribute to the Y1 result of $>31.5 \%$.

Besides, (X10 - Naphtha Feed Flow) vs (X3 Integral Burner Flow) and (X10 - Naphtha Feed Flow) vs (X7 - SHP BFW Flow) may not much favor towards higher (Y1 - Ethylene Yield) with limitation of predicted process range at the studied plant taken from 3,798 data for Regression model earlier. For both conditions, the lower reading of X10 combined with lower X3 and X7 will result in lower Y1.

Fig. 3 shows the Surface Plot of variables with the four lowest P-Values towards Y1. The 3D Surface Plot is a three-dimensional graph that is useful for investigating desirable response values for two continuous variables based on the model equation towards fitted response value, Y1. The value for non-tested variables was held at mean value, $\bar{x}$ of $10624.29,586.04,106.79$, and 61.22 for X2, X3, X7, and X10 respectively. The light on the Surface Plot was also set to indicate Y1 Value at maximum.

From the Surface Plot in Fig. 3 (a) - 3 (c) the lower value of (X2 - Hearth Burner Flow) combined with the higher value of (X3 - Integral Burner Flow), (X7 - SHP BFW Flow), and (X10 - Naphtha Feed Flow) resulted in higher (Y1 - Ethylene Yield). These combinations also showed that more Y1 can be obtained when the other variables were put at the constant mean values.

Besides, Fig. 3 (d) and Fig. 3 (e) show that the higher (X3 - Integral Burner Flow) combined with higher (X7 - SHP BFW Flow) and (X10 - Naphtha Feed Flow) will result in higher (Y1 - Ethylene Yield). The same condition also was seen in Fig. 3 (f) for (X7 - SHP BFW Flow) vs (X10 - Naphtha Feed Flow). However, manipulating these relationships while putting others at constant mean value was generating less $\mathrm{Y} 1$ compared to manipulating Fig. 3 (a) -3 (c).

Table 4 shows the Multiple Response Prediction while Fig. 4 shows the setting of significant variables in achieving maximized Ethylene Yield (Y1) in the studied plant utilizing the Response Optimizer tool.

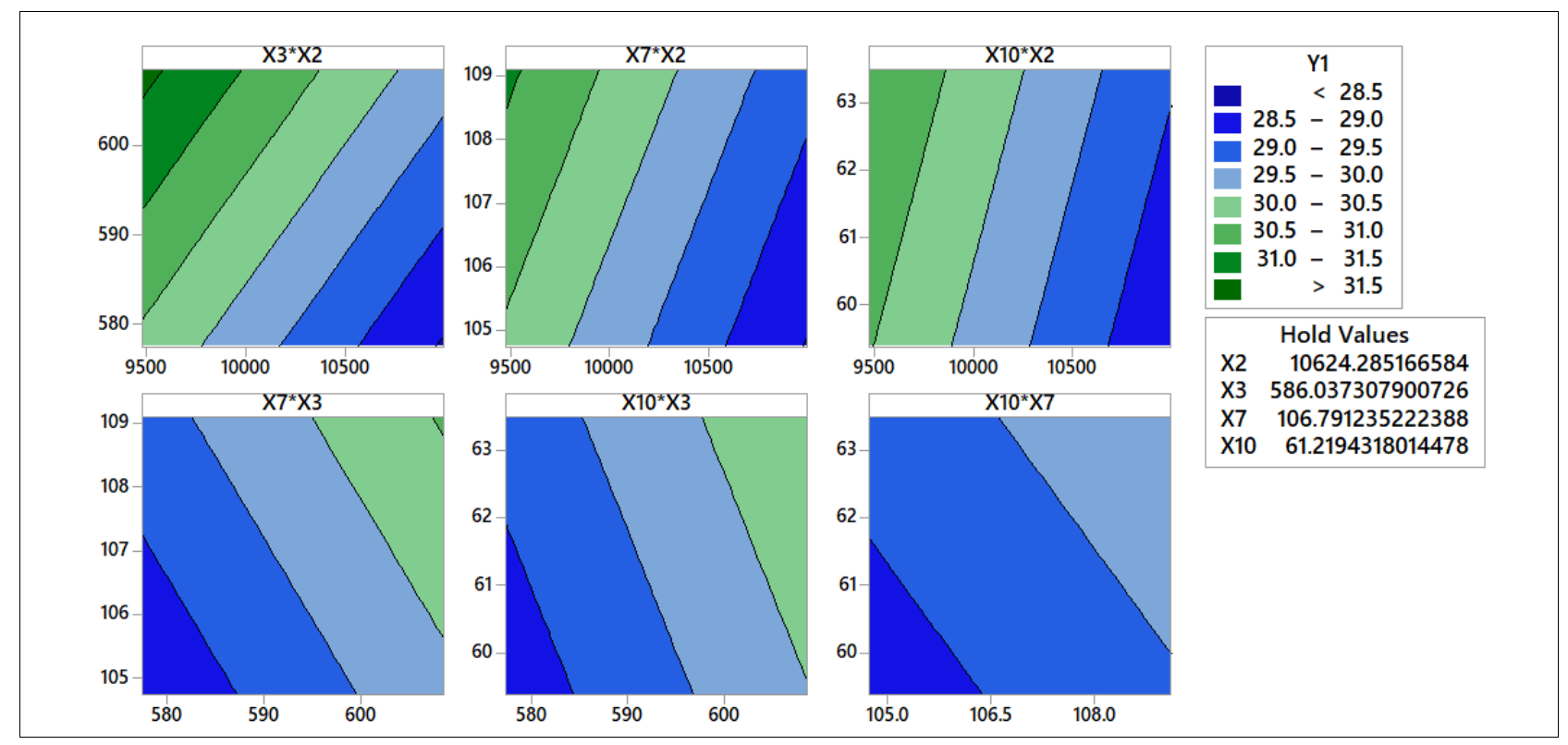

Fig. 2. Contour Plot of Output Y1 against variables with the lowest P-Value; X2, X3, X7, and X10

\footnotetext{
* Corresponding author: mohamadhafizi.zakri@prefchem.com;
} 


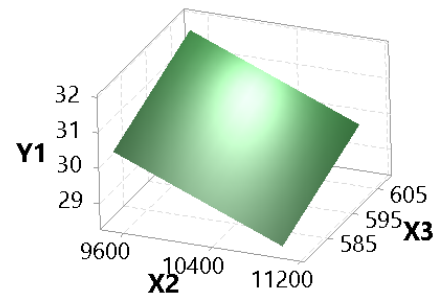

(a)

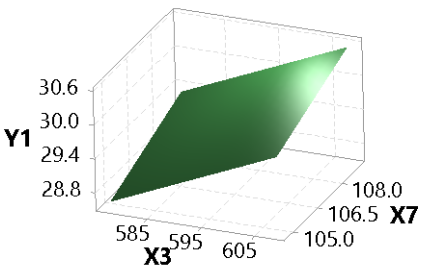

(d)

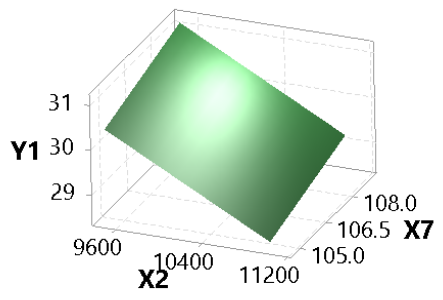

(b)

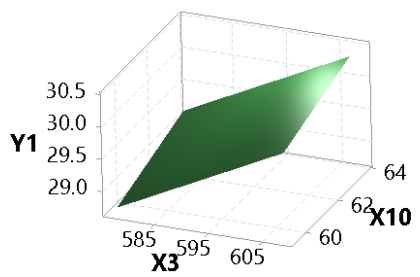

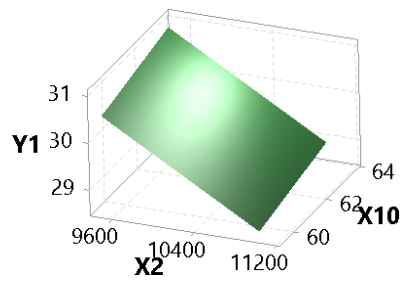

(c)

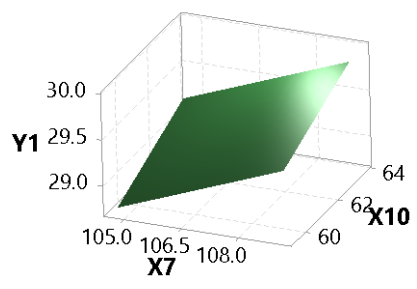

(f)

Fig. 3. Surface Plot of $Y 1$ against significant variables of (a) X2 vs X3, (b) X2 vs X7, (c) X2 vs X10, (d) X3 vs X7 (e) X3 vs X10 and (f) X7 vs X10.

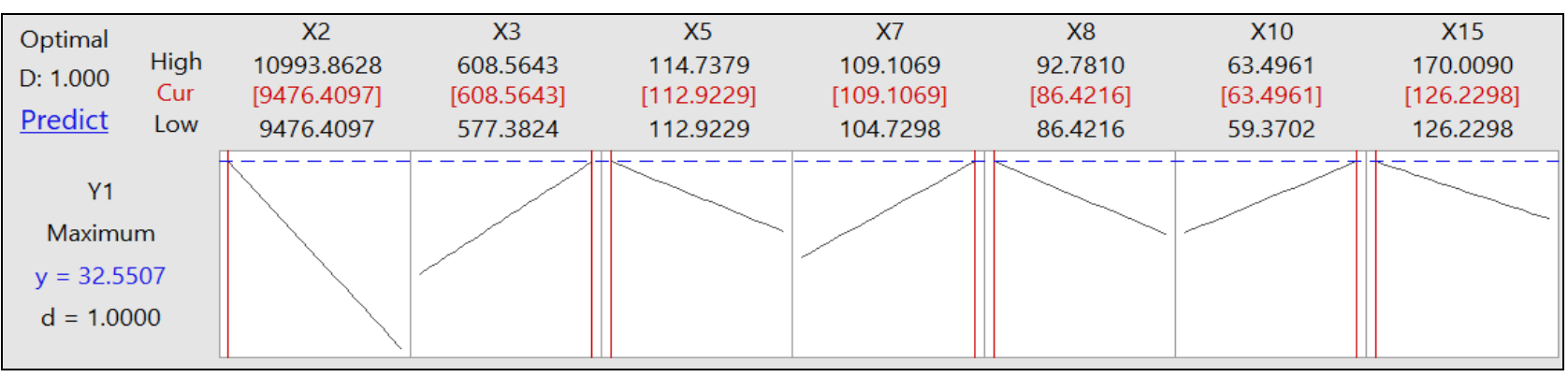

Fig. 4. Response Optimizer prediction for significant operating variables to achieve maximum Y1

Table 4. Multiple Response Prediction

\begin{tabular}{|c|c|c|c|c|}
\hline \multirow{2}{*}{ Response } & \multirow{2}{*}{ Fit } & \multirow{2}{*}{ SE Fit } & \multicolumn{2}{|c|}{ Confidence } \\
\cline { 4 - 5 } & & & $\mathbf{9 5 \%}$ CI & $\mathbf{9 5 \%}$ PI \\
\hline \multirow{2}{*}{ Y1 } & \multirow{2}{*}{32.551} & 0.214 & $\begin{array}{c}(32.129, \\
32.972)\end{array}$ & $\begin{array}{c}(31.928, \\
33.174)\end{array}$ \\
\hline
\end{tabular}

This study showed that the Ethylene Yield can be maximized at $32.55 \%$ using Response Optimizer in Minitab software. The recommended process parameters to achieve this value were $9,476.41 \mathrm{~kg} / \mathrm{hr}$ of Hearth Burner Flow, $608.56 \mathrm{~kg} / \mathrm{hr}$ of Integral Burner Flow, 112.93 Barg of Steam Drum Pressure, 109.11 t/hr of SHP BFW Flow, 86.42 t/hr of SHP Flow, $63.49 \mathrm{t} / \mathrm{hr}$ of Naphtha Feed Flow and $126.23 \mathrm{mg} / \mathrm{m}^{3}$ of Stack NOx Emission. The High and Low range setting in Fig. 4 may be used as a guide for the Operations staff at the studied plant.to maximize the Ethylene Yield.

However, the analysis of these Regression models, Contour Plot, Surface Plot, and Response Optimizer was limited to the process range of actual 3,798 historical data used earlier in the Regression analysis. Besides, this study also emphasized model development for Ethylene Yield that focused only on the Naphtha Feed with Paraffins, Olefins, Naphthenes, and Aromatics (PONA) composition shown in Table 1. It is recommended for future studies with huge variations of PONA composition to also apply the same methodology as discussed in Section 2 as it was proven successful in this study.

\section{Conclusion}

The model for Ethylene Yield in the studied plant successfully developed using Regression analysis in the Minitab Software Version 18. The Ethylene Yield can be maximized via good control and continuous monitoring to the most important parameters in the Regression model which were Steam Drum Pressure, SHP BFW Flow, and Naphtha Feed Flow. The highest Ethylene Yield that can be obtained from the mathematical model is $32.55 \%$ by utilizing the recommended setting in the Response Optimizer tool.

The authors would like to express sincere gratitude to the Pengerang Refining Company Sdn Bhd for providing stable and reliable operation during the study period.

\footnotetext{
*Corresponding author: mohamadhafizi.zakri@prefchem.com;
} 


\section{References}

1. Z. Feli, A. Darvishi, A. Bakhtyari, M.R. Rahimpour, S. Raeissi, J. Taiwan Inst. Chem. Eng. 81, 1-13 (2017).

2. M.H. Zakria, A.A. Omar, M.A. Bustam, Procedia Eng. 148, 561-567 (2016).

3. H. Shi, C. Su, J. Cao, P. Li, J. Liang, G. Zhong, Ind. Eng. Chem. Res. 54, 1849-1860 (2015).

4. H. Song, C.-1. Su, H. Shi, P. Li, J.-t. Cao, Meas. Control. 52, 526-539 (2019).

5. R. Van de Vijver, N. Vandewiele, P. Bhoorasingh, B. Slakman, F. Seyedzadeh Khanshan, H.H. Carstensen, M.F. Reyniers, B. Marin, R. West, K. Van Geem, Int. J. Chem. Kinet. 47, 199-231 (2015).

6. S. Vangaever, P.A. Reyniers, S.H. Symoens, N.D. Ristic, M.R. Djokic, G.B. Marin, K.M. Van Geem, Chem. Eng. Res. Des. 153, 380-390 (2020).

7. T.-J. Fan, R. Luo, H. Xia, X. Li, Nat. Hazards. 75, 319-332 (2015).

8. I.K. Nikolaidis, L.F.M. Franco, L.N. Vechot, I.G. Economou, Fluid Phase Equilib. 470, 149-163 (2018).

9. S. Gong, C. Shao, L. Zhu, Chin. J. Chem. Eng. 25, 793-799 (2017).

10. D.Y. Caballero, L.T. Biegler, R. Guirardello, Comput. Aided Chem. Eng. 37, 917-922 (2015).

11. V. Kuritsyn, D. Arapov, A. Ekimova, A. Yakupov, Chem. Technol. Fuels Oils. 44, 180-189 (2008).

12. H. Karimi, E. Cowperthwaite, B. Olayiwola, H. Farag, K. McAuley, Can. J. Chem. Eng. 96, 33-48 (2017).

13. M. Masoumi, S.M. Sadrameli, J. Towfighi, A. Niaei, Energy. 31, 516-527 (2006).

14. Z. Junfeng, P. Zhiping, C. Delong, L. Qirui, H. Jieguang, Q. Jinbo, IEEE Access. 7, 158643158654 (2019).

15. Z. Wang, Z. Li, Y. Feng, G. Rong, Can. J. Chem. Eng. 94, 1723-1739 (2016).

16. I. Kucora, P. Paunjoric, J. Tolmac, M. Vulovic, J. Speight, L. Radovanovic, Pet. Sci. Technol. 35, 213-221 (2017).

17. X. Sun, L. Shen, Corros. Sci. Prot. Technol. 29, 575-580 (2017).

18. Z. Peng, J. Zhao, Z. Yin, Y. Gu, J. Qiu, D. Cui, Processes. 7, 909 (2019).

19. L. Shen, J. Gong, H. Liu, Appl. Mech. Mater. 750, 192-197 (2015).

20. J.F. Hair, R.E. Anderson, R.L. Tatham, W.C. Black, Multivariate Data Analysis with Readings (Prentice-Hall, New Jersey, United States, 1995).

21. C. Ringle, S. Wende, J.-M. Becker SmartPLS 3. 2015.

22. P.D. Haaland, Experimental design in biotechnology (Marcel Dekker, New York, United States, 1989).

23. W.N.N. Wan Omar, N. Nordin, M. Mohamed, N.A. Saidina Amin, J. Appl. Sci. 9, 3098-3103 (2009). 